\title{
Effect of Poverty on Intertemporal Choice and Psychological Explanations
}

\author{
Shaoli Yang \\ School of Management, Jinan University, Guangzhou, China \\ Email: yangshaoli199233@163.com
}

How to cite this paper: Yang, S. L. (2016). Effect of Poverty on Intertemporal Choice and Psychological Explanations. Psychology, 7, 1296-1306.

http://dx.doi.org/10.4236/psych.2016.710131

Received: August 22, 2016

Accepted: September 16, 2016

Published: September 19, 2016

Copyright (@) 2016 by author and Scientific Research Publishing Inc. This work is licensed under the Creative Commons Attribution International License (CC BY 4.0).

http://creativecommons.org/licenses/by/4.0/

\begin{abstract}
In recent years, with global sustainable economic development, poverty is still one of the most pressing issues facing in the world. Many poor families have to face in their daily lives the complex and difficult economic decisions, and often the poor and the rich in these intertemporal preferences are different. Studies show that poverty will impact intertemporal choice through two intermediary paths: cognition and emotion. The poor prefer smaller and sooner choice other than larger and later choice. Future studies may pay attention to: absolute poverty and relative poverty, different effects on intertemporal choice; cognition and emotion, the two psychological mechanisms of interaction and intercultural studies.
\end{abstract}

\section{Keywords}

Poverty, Intertemporal Choice, Cognitive Capacity, Emotion

\section{Introduction}

Poverty is still one of the most pressing issues facing in the world (Haushofer \& Fehr, 2014). Poverty is a multidimensional concept, and by its very nature, which can be seen as a lack of sufficient wealth and income (Ravallion \& Bidani, 1994). Currently there are $14.5 \%$ people worldwide (about 1.015 billion) living on less than 1.25 dollars a day, with more than 150 million people living on less than 1 dollar a day (WHO, 2013). Although in recent years, with global sustainable economic development, the population of poverty has decreased, poverty has still not been effectively resolved. The purpose of development is to benefit all members of society, so we should pay special attention to the poor, and to improve the lives of the poor must become a priority in our agenda (Kanbur \& Squire, 1999).

Decision-making behaviors take places throughout our human life every day. Intertemporal choice is one of the highlights in behavioral decision and related fields nearly 
twenty years (Liang \& Liu, 2011). Intertemporal choices are decisions involving tradeoffs among costs and benefits occurring at different times (Frederick, Loewenstein, \& O'donoghue, 2002). In the study of intertemporal choice, in order to compare results at different times viewed by a psychological perspective, researchers introduced the concept of time discounting (Samuelson, 1937), that is, delay rewards are discounted at a rate over time. Generally researchers use the discounting rate to measure the degree to which people discount future events. Studying time discounting is helpful to explore the psychological process of intertemporal choice. Time discounting rate increases indicate that individual prefers more immediate rewards, and the value of delay reward declines more rapidly over time. Time discounting is the core concept to understand intertemporal choice. Intertemporal choices are decisions with consequences that play out over time which are important and ubiquitous. Decisions about spending, investments, diet, relationships, fertility, crime and education all contain intertemporal tradeoffs (Berns, Laibson, \& Loewenstein, 2007). Intertemporal choice not only affects personal health, wealth and happiness, but also the nation's economic prosperity as first suggested by Adam Smith (Frederick, Loewenstein, \& O'Donoghue, 2002). People in daily life often make various economic decisions. Many low-income families have to face complex and difficult intertemporal economic choices (Collins, Morduch, Rutherford, \& Ruthven, 2009), concerning to savings and education investment. Some studies showed that poor and rich people in these intertemporal choices had different select tendencies. Poor people are unwilling to invest in the program which can obtain long-term benefits, for example education and medical health. Consequently, the short-sighted decisions will further reduce poor people long-term gains for the future (Haushofer \& Fehr, 2014).

The cause of poverty has many reasons. Previous studies on poverty are always taking the macro perspective (Badrudin \& Warokka, 2012; Lu \& Lu, 2013). However, psychological processes of poverty gradually come into discussions in recent years. Psychologists unite scholars from other fields arrange a series of laboratory experiments and field experiments around the relationship between poverty and intertemporal choice. There comes to different conclusions due to experimental paradigms adopted to understand poverty-related psychological decision from micro perspective. This paper aims at summarizing these studies and exploring the psychological mechanism of poverty related with intertemporal choice. Studies show that poverty will impact intertemporal choice through two intermediary paths: cognition and emotion. The poor prefer smaller and sooner choice other than larger and later choice.

\section{The Relationship between Poverty and Intertemporal Choice}

Intertempoal choice affects a series of behaviors, such as savings, loans, investments (including education), exercise and fertility (Anderson, Dietz, Gordon, \& Klawitter, 2004). In real life, compared to the rich, the poor display more varieties of adverse behaviors such as excessive drinking and overeating. And the poor are always excessive borrowing and seldom making investment in education and savings. Although people clearly know those behaviors are harmful, some people would rather give up the 
long-term benefit for the instant gratification. If people's discounting rate is high, they are often reluctant to send their children to accept years of education. Because they think education is an investment for future earnings that they cannot wait (Tanaka, Camerer, \& Nguyen, 2016). Studies also show that compared to rich countries, poor countries tend to saving less, eating less healthy food and exercising less (Fehr \& Falk, 2002). Economic theories and empirical evidences both indicate that poor families are less likely to give up the present gains for future bigger and longer benefits. Whether poverty makes people "shortsighted" and prefer smaller and shorter gains in the intertemporal choice? What is the relationship between poverty and intertemporal choice?

As early as 1930 Fisher made a point that "in the same condition, people with lowincome tend to have a higher time discounting rate. Partly because they consider that necessities are necessary both for the present and the future, and partly because of the lack of foresight and self-control". Later studies provide evidences for this view. There are many studies about the relationship between discounting rate and income in developed and developing countries (Tanaka, Camerer, \& Nguyen, 2016). There are many studies have found that people who live in poverty, especially in developing countries, tend to discount future benefits more than the rich. For example, in America the time discounting rate of poor family is higher than rich family (Lawrance, 1991). Similarly, researchers found that farm families in Ethiopia (Yesuf \& Bluffstone, 2008) and the research samples in the South India (Pender, 1996) both show that lower levels of wealth predict quite high time discounting rate (by measure). Researcher used the family data of purchasing and using air-conditions to estimate the time discounting rate of consumer, and study showed that the relationship between time discounting rate and income is reverse (Hausman, 1979). There are studies showing that the relationship between discounting rate and wealth is negative correlation in the United States and Denmark, that is to say, the wealthier people are more patience (Lawrance, 1991; Harrison, Lau, \& Williams, 2002). Researcher also found negative correlation between wealth and discounting rate in Madagascar (Nielsen, 2001). And researchers found that the discounting rate of subjects with high-income participants is lower than the low-income participants' (Green et al., 1996).

In addition to the study of the correlation between income and time discounting, there is also evidence that poverty has causal effect on time discounting. Researchers used experimental method to measure the negative correlation between time discounting rate and income in Vietnam (Tanaka, Camerer, \& Nguyen, 2016). That is to say, poor households prefer choosing smaller and shorter reward (SS) to choosing larger and later reward (LL). In the study, through the use of rainfall as a tool variable of income to predict and confirm the negative relationship between discounting rate and income, this finding suggests that poverty has causal effect on time discounting.

Studies have shown that status of rich and poor can change delay discounting rate of individual, letting people make different choices in intertemporal decisions. In poor condition, individual would rather choose smaller and shorter rewards than delayed bigger rewards (Liu et al., 2012). In the study, researchers conduct three experiments: one is that priming the poor cues and rich cues explicitly, two is that priming the poor cues and rich 
cues implicitly, three is that manipulating the change of status between poor and rich temporarily. And the findings suggest that individual in the poor status is more impulsive to some extent, thus they pursue instant gratification in intertemporal choice.

But there are also some studies do not support this view. For example, researchers had not found significant correlation between time discounting and wealth in Bolivia and Vietnam (Kirby et al., 2002; Anderson, Dietz, Gordon, \& Klawitter, 2004). However, they only used two villages with similar characteristics in their research, so that the income changes between samples are too small. Therefore, researchers may not have enough income changes to explore the relationship between income and time discounting (Anderson, Dietz, Gordon, \& Klawitter, 2004). If using villages that have larger income changes as samples, researchers are likely to find possible relationship between income and time discounting.

In summary, although a small number of studies suggest that there is no relationship between income and time discounting rate. Most studies suggest that income has a negative relationship with discounting rate, that is to say, poverty will produce higher discounting rate, and the poor tend to choose smaller and sooner rewards in intertemporal choices. This paper supports the idea that poverty has effect on intertemporal choice through reviewing relevant literatures. Some researches focus on poor environmental conditions (such as restricted in the credit market) to explain the poor series of bad behavior, which in turn lead to further deepening of poverty (Banerjee \& Duflo, 2008). While some researches focus on the characteristics of the poor themselves, such as rarely received good education, less parental attention and vulnerable to negative shocks (Haushofer, Schunk, \& Fehr, 2013), this paper focuses primarily on the poor's psychological process to explore the impact of poverty on intertemporal choice. Why is this happening? Numerous studies show that may exist some psychological variables to regulate the relationship between poverty and intertemporal choice. Next, we discuss the psychological mechanisms between them.

\section{Psychological Mechanisms of Poverty Impact Intertemporal Choice}

By reviewing related literature, this paper suggests that poverty will impact intertemporal choice through two intermediary paths: cognition and emotion, which will make people prefer smaller and sooner choice other than larger and later choice in intertemporal choice (see Figure 1).

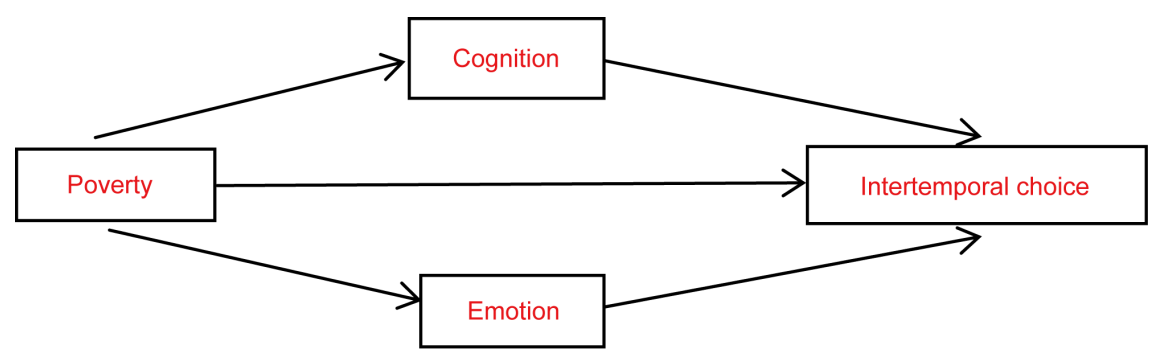

Figure 1. Two psychological paths. 


\subsection{Through Cognitive Path}

Human cognitive system only has limited capacity (Baddeley \& Hitch, 1974; Luck \& Vogel, 1997; Neisser, 1976). Urgent budgetary concerns dominate the mind, so there are fewer available cognitive resources to guide people's decisions and actions. When the poor worry about money problems, they will lose the ability to make full consideration for the other issues (Mani, Mullainathan, Shafir, \& Zhao, 2013). For the poor, the same economic decision for them means to make difficult tradeoffs among less mistakes and more valuable alternatives (Spears, 2010). There are experimental evidences showing that these difficult decisions will consume cognitive resources (Vohs et al., 2014; Tversky \& Shafir, 1992). Researchers used two different but complementary study designs to test the causal relationship between poverty and cognitive function (Butterworth, Cherbuin, Sachdev, \& Anstey, 2012). In the laboratory study, researchers conducted a series of experiments towards consumers in a New Jersey shopping mall. Participants were asked to imagine themselves encounter some specific economic events (for example, spend money to fix the car), and these economic events are divided into "easy" or "difficult" two grades based on expenditures (such as car repair will cost \$150 or $\$ 1500)$, then participants need to think about coping approach. Subsequently, participants will receive the Raven's standard progressive testing (RPM) and spatial coordination testing. The former tests logical thinking and the ability of solving new problems, and the latter tests cognitive control. Results showed that when participants encounter "easy" event, the performance of high-income people and low-income people are the same. But when participants encounter "difficult" event, cognitive ability of low-income people is declined significantly, however, high-income people maintain the original performance. In the field study, researchers tested cognitive ability changes among sugarcane growers before and after the harvest in India. Sugarcane growers experienced the cycle of poverty before the harvest and rich after the harvest. Therefore, this allows us to compare the same farmers' cognitive abilities in poor (prior to harvest) and rich (post harvest) condition. Performance of cognitive test of sugarcane growers before the harvest is not good. But after the harvest their cognitive abilities are significantly improved.

Intertemporal choice is a common human decision making activity. It may involve cognitive components and is associated with working memory, especially the central executive of working memory. Because cognitive abilities are highly related to working memory capacity (Colom \& Shih, 2004; Benjamin, Brown, \& Shapiro, 2013), and involve overlapping brain regions (Gray \& Thompson, 2004). Cognitive ability and working memory capacity and time discounting share the brain process, so they are related (Shamosh et al., 2008). Researchers found that truck drivers who perform excellent in cognitive test tend to choose delay of reward in intertemporal choice task (Burks, Carpenter, Götte et al., 2008). Adding individual working memory load will occupy cognitive resources, resulting in a higher discounting rate (Hinson, Jameson, \& Whitney, 2003). Some research data shows that delay discounting may be related to working memory (Hinson, Jameson, \& Whitney, 2003). When increasing working memory load, 
value of delayed reward is dropping, and discounting rate is increasing.

Therefore, poverty through impeding cognitive ability thus impacting intertemporal choice, making people prefer smaller and sooner options.

\subsection{Through Emotional Path}

Many studies show that poverty often leads to negative emotions, and poverty reduction has the opposite effect (Haushofer \& Fehr, 2014). Anxiety and depression are common negative emotions, and they are two typical negative emotions that are most closely related to physical and mental health (Fan, 2007; Tu \& Guo, 2011). Studies show that level of negative emotion of impoverished college students is significantly higher than the non-poor student's (Fan, 2007). And the poor college students' level of depression is significantly higher than non-poor students' (Xue, Lu, \& Liang, 2010). Numerous studies show that income is negative related to depression (Fiscella \& Franks, 1997), and there is a negative linear relationship between income and anxiety (Wittchen, Zhao, Kessler, \& Eaton, 1994). Researches from psychology and biology show that poverty leads to anxiety and unhappiness (Sheehy-Skeffington \& Haushofer, 2014).

Studies have shown that different emotional states affect individual's intertemporal choice (Peng \& Feng, 2014). Emotions are important factors affecting the intertemporal choice, and under different emotion priming state the future result's value is different. Recently, many studies suggest that negative emotions increase time discounting (Lerner, Li, \& Weber, 2012; Ifcher \& Zarghamee, 2011; DeSteno et al., 2014).

Researchers through showing participants the short films which cause sadness emotion, and then let participants make money intertemporal choice between smaller and sooner rewards and lager and later rewards (Lerner, Li, \& Weber, 2012). Study results show that compare to control group participants, participants watch short films that trigger sadness prefer to choose smaller and sooner rewards. That is to say, sadness reduces people's patience. To the contrary, in another recent study show that participants watch short films which trigger positive emotion tend to be more patience in the same task (Ifcher \& Zarghamee, 2011). Studies have shown that in the presence of negative expected emotions, participants are more likely to choose immediate and smaller rewards.

Therefore, poverty through triggering negative emotions thus impacting intertemporal choice, making people prefer smaller and sooner options.

\section{Prospects}

Seen from the conclusions of psychology studies, the problem of poverty goes beyond the traditional economic. Poverty has a significant impact on individual's cognition and emotion, thus making people myopic and tend to choose immediate and smaller option in intertemporal choice. Therefore, it is more difficult for the poor to escape the poverty trap. Although there are already some research findings about the impact of poverty on the intertemporal choice, there are still some issues to be discussed. 


\subsection{Whether Absolute Poverty or Relative Poverty Has Impact on Intertemporal Choice Needs to Be Further Studied}

In traditional economic, there are arguments about absolute poverty and relative poverty. Absolute poverty means that poverty is absolute existence in essence. That is to say, the core meaning of absolute poverty is that individual lacking of capacity of acquiring basic material opportunity and the measurement standard is also absolute (Sen, 1983). Relative poverty means that poverty is compared with others and poverty can change with social norms and customs (Townsend, 1962). However, most of the existing research has avoided discussing whether to use absolute poverty or relative poverty as term (Banerjee, Deaton, \& Duflo, 2004). We cannot compare the absolute level of discounting rate between America, Israel and Vietnam, because specific question is different in different studies and different dollar terms. Therefore, the study of poverty should integrate the argument of absolute poverty and relative poverty in future research.

\subsection{Single Psychological Mechanism Cannot Always Explain the Impact of Poverty on Intertemporal Choice}

There might be interactions between a variety of psychological variables, for example, cognition and emotion. These two aspects are inseparable. People's decision is affected by emotions. Researchers induce participants' positive emotion through pictures and words (Pyone \& Isen, 2011). And the results show that people with positive emotion are more far-sighted and more concerned about the future, so they have better self-control ability. In the light of construction theory, people with positive emotion have high level of construction, so they are more likely to choose future higher income option.

\subsection{Any Research Topic in Psychology Needs to Take Account of the Cultural Background}

Most of the above conclusions are based on studies abroad, and China has just started related studies. Those conclusions whether can be extended to China remain future empirical study of localization. Intertemporal choice may exist differences between different regions, races and cultures (Liang \& Liu, 2011). For example, some researchers use the date from United States, finding that there is negative relationship between income and discounting rate (Green et al., 1996; Hausman, 1979). But other researchers use the same measurement in Bolivia's study, and do not find there is significant correlation between income and discounting rate. Cultural differences may be one of the reasons for this difference (Kirby et al., 2002). The negative relationship between income and discounting rate may be cultural acquisition. Many sociological evidences support this view (Cohen \& Hodges, 1963; O'Rand \& Ellis, 1974). For example, in the economic and psychology analysis of time discounting, researchers argue that socioeconomic factors have important effect on children's delay of gratification. According to this view, the negative relationship between time discounting and income at least partly reflects deep level of cultural differences. 


\section{References}

Anderson, C. L., Dietz, M., Gordon, A., \& Klawitter, M. (2004). Discount Rates in Vietnam. Economic Development and Cultural Change, 52, 873-887. http://dx.doi.org/10.1086/381111

Baddeley, A. D., \& Hitch, G. (1974). Working Memory. Psychology of Learning and Motivation, 8, 47-89. http://dx.doi.org/10.1016/S0079-7421(08)60452-1

Badrudin, R., \& Warokka, A. (2012). Poverty Measurement and Choice of Poverty Reduction Strategy: The Importance of Poverty Measurement in Determining the Right Strategy. Journal of Economics and Behavioral Studies, 4, 595-602.

Banerjee, A. V., \& Duflo, E. (2008). What Is Middle Class about the Middle Classes around the World? The Journal of Economic Perspectives, 22, 3-41. http://dx.doi.org/10.1257/jep.22.2.3

Banerjee, A., Deaton, A., \& Duflo, E. (2004). Health, Health Care, and Economic Development: Wealth, Health, and Health Services in Rural Rajasthan. The American Economic Review, 94, 326-330. http://dx.doi.org/10.1257/0002828041301902

Benjamin, D. J., Brown, S. A., \& Shapiro, J. M. (2013). Who Is "Behavioral"? Cognitive Ability and Anomalous Preferences. Journal of the European Economic Association, 11, 1231-1255. http://dx.doi.org/10.1111/jeea.12055

Berns, G. S., Laibson, D., \& Loewenstein, G. (2007). Intertemporal Choice toward an Integrative Framework. Trends in Cognitive Sciences, 11, 482-488. http://dx.doi.org/10.1016/j.tics.2007.08.011

Burks, S. V., Carpenter, J., Götte, L., Monaco, K., Porter, K., \& Rustichini, A. (2008). Using Behavioral Economic Field Experiments at a Firm: The Context and Design of the Truckers and Turnover Project. In S. Bender, J. Lane, \& K. L. Shaw (Eds.), The Analysis of Firms and Employees: Quantitative and Qualitative Approaches (pp. 45-106). Chicago, IL: University of Chicago Press. http://dx.doi.org/10.7208/chicago/9780226042893.003.0003

Butterworth, P., Cherbuin, N., Sachdev, P., \& Anstey, K. J. (2012). The Association between Financial Hardship and Amygdala and Hippocampal Volumes: Results from the PATH through Life Project. Social Cognitive and Affective Neuroscience, 7, 548-556. http://dx.doi.org/10.1093/scan/nsr027

Cohen, A. K., \& Hodges, H. M. (1963). Characteristics of the Lower-Blue-Collar-Class. Social Problems, 10, 303-334. http://dx.doi.org/10.2307/799204

Collins, D., Morduch, J., Rutherford, S., \& Ruthven, O. (2009). Portfolios of the Poor: How the World's Poor Live on \$2 a Day. Princeton, NJ: Princeton University Press.

Colom, R., \& Shih, P. C. (2004). Is Working Memory Fractionated onto Different Components of Intelligence? A Reply to Mackintosh and Bennett (2003). Intelligence, 32, 431-444.

http://dx.doi.org/10.1016/j.intell.2004.06.011

DeSteno, D., Li, Y., Dickens, L., \& Lerner, J. S. (2014). Gratitude: A Tool for Reducing Economic Impatience. Psychological Science, 25, 1262-1267.

http://dx.doi.org/10.1177/0956797614529979

Fan, R. F. (2007). The Study on Impoverished University Student's Negative Emotions and the Effecting Factors. Master Dissertation, Nanjing: Hohai University.

Fehr, E., \& Falk, A. (2002). Psychological Foundations of Incentives. European Economic Review, 46, 687-724. http://dx.doi.org/10.1016/S0014-2921(01)00208-2

Fiscella, K., \& Franks, P. (1997). Poverty or Income Inequality as Predictor of Mortality: Longitudinal Cohort Study. BMJ, 314, 1724-1727. http://dx.doi.org/10.1136/bmj.314.7096.1724

Frederick, S., Loewenstein, G., \& O'donoghue, T. (2002). Time Discounting and Time Preference: A Critical Review. Journal of Economic Literature, 40, 351-401. 
http://dx.doi.org/10.1257/jel.40.2.351

Gray, J. R., \& Thompson, P. M. (2004). Neurobiology of Intelligence: Science and Ethics. Nature Reviews Neuroscience, 5, 471-482. http://dx.doi.org/10.1038/nrn1405

Green, L., Myerson, J., Lichtman, D., Rosen, S., \& Fry, A. (1996). Temporal Discounting in Choice between Delayed Rewards: The Role of Age and Income. Psychology and Aging, 11, 7984. http://dx.doi.org/10.1037/0882-7974.11.1.79

Harrison, G. W., Lau, M. I., \& Williams, M. B. (2002). Estimating Individual Discount Rates in Denmark: A Field Experiment. The American Economic Review, 92, 1606-1617. http://dx.doi.org/10.1257/000282802762024674

Haushofer, J., \& Fehr, E. (2014). On the Psychology of Poverty. Science, 344, 862-867. http://dx.doi.org/10.1126/science.1232491

Haushofer, J., Schunk, D., \& Fehr, E. (2013). Negative Income Shocks Increase Discount Rates. Zurich: University of Zurich Working Paper.

Hausman, J. A. (1979). Individual Discount Rates and the Purchase and Utilization of EnergyUsing Durables. The Bell Journal of Economics, 10, 33-54. http://dx.doi.org/10.2307/3003318

Hinson, J. M., Jameson, T. L., \& Whitney, P. (2003). Impulsive Decision Making and Working Memory. Journal of Experimental Psychology: Learning, Memory, and Cognition, 29, 298-306. http://dx.doi.org/10.1037/0278-7393.29.2.298

Ifcher, J., \& Zarghamee, H. (2011). Happiness and Time Preference: The Effect of Positive Affect in a Random-Assignment Experiment. The American Economic Review, 101, 3109-3129. http://dx.doi.org/10.1257/aer.101.7.3109

Kanbur, R., \& Squire, L. (1999). The Evolution of Thinking about Poverty: Exploring the Interactions Mimeographed Document. Washington DC: World Development Report Office, Washington DC World Bank.

Kirby, K. N., Godoy, R., Reyes-Garcia, V., Byron, E., Apaza, L., Leonard, W., Wilkie, D. et al. (2002). Correlates of Delay-Discount Rates: Evidence from Tsimane' Amerindians of the Bolivian Rain Forest. Journal of Economic Psychology, 23, 291-316. http://dx.doi.org/10.1016/S0167-4870(02)00078-8

Lawrance, E. C. (1991). Poverty and the Rate of Time Preference: Evidence from Panel Data. Journal of Political Economy, 99, 54-77. http://dx.doi.org/10.1086/261740

Lerner, J. S., Li, Y., \& Weber, E. U. (2012). The Financial Costs of Sadness. Psychological Science, 24, 72-79. http://dx.doi.org/10.1177/0956797612450302

Liang, Z. Y., \& Liu, H. (2011). Exploring the Nature of Intertemporal Choice. Advances in Psychological Science, 19, 959-966.

Liu, L., Feng, T., Suo, T., Lee, K., \& Li, H. (2012). Adapting to the Destitute Situations: Poverty cues Lead to Short-Term Choice. PLOS ONE, 7, e33950. http://dx.doi.org/10.1371/journal.pone.0033950

Lu, S. F., \& Lu, H. Y. (2013). Could Government Assistance Help the Poor to Alleviate Poverty? Empirical Study Based on the Data of CHNS from 1989 to 2009. Journal of Finance and Economics, 39, 4-16.

Luck, S. J., \& Vogel, E. K. (1997). The Capacity of Visual Working Memory for Features and Conjunctions. Nature, 390, 279-281. http://dx.doi.org/10.1038/36846

Mani, A., Mullainathan, S., Shafir, E., \& Zhao, J. (2013). Poverty Impedes Cognitive Function. Science, 341, 976-980. http://dx.doi.org/10.1126/science.1238041

Neisser, U. (1976). Cognition and Reality: Principles and Implications of Cognitive Psychology. 
New York: WH Freeman and Company.

Nielsen, U. (2001). Poverty and Attitudes towards Time and Risk: Experimental Evidence from Madagascar. Copenhagen: Royal Veterinary and Agricultural University.

O’Rand, A., \& Ellis, R. A. (1974). Social Class and Social Time Perspective. Social Forces, 53, 5362. http://dx.doi.org/10.1093/sf/53.1.53

Pender, J. L. (1996). Discount Rates and Credit Markets: Theory and Evidence from Rural India. Journal of Development Economics, 50, 257-296. http://dx.doi.org/10.1016/S0304-3878(96)00400-2

Peng, J., \& Feng T. Y. (2014). Intervention Program and Neural Mechanisms for Intertemporal Choice in Addicts. Advances in Psychological Science, 5, 810-821.

Pyone, J. S., \& Isen, A. M. (2011). Positive Affect, Intertemporal Choice, and Levels of Thinking: Increasing Consumers' Willingness to Wait. Journal of Marketing Research, 48, 532-543. http://dx.doi.org/10.1509/jmkr.48.3.532

Ravallion, M., \& Bidani, B. (1994). How Robust Is a Poverty Profile? The World Bank Economic Review, 8, 75-102. http://dx.doi.org/10.1093/wber/8.1.75

Samuelson, P. A. (1937). A Note on Measurement of Utility. The Review of Economic Studies, 4, 155-161. http://dx.doi.org/10.2307/2967612

Sen, A. (1983). Poor, Relatively Speaking. Oxford Economic Papers, 35, 153-169.

Shamosh, N. A., DeYoung, C. G., Green, A. E., Reis, D. L., Johnson, M. R., Conway, A. R., Gray, J. R. et al. (2008). Individual Differences in Delay Discounting Relation to Intelligence, Working Memory, and Anterior Prefrontal Cortex. Psychological Science, 19, 904-911. http://dx.doi.org/10.1111/j.1467-9280.2008.02175.x

Sheehy-Skeffington, J., \& Haushofer, J. (2014). The Behavioural Economics of Poverty. In Barriers to and Opportunities for Poverty Reduction (pp. 96-112). UNDP.

Spears, D. E. (2010). Economic Decision-Making in Poverty Depletes Behavioral Control. Princeton, NJ: Center for Economic Policy Studies, Princeton University.

Tanaka, T., Camerer, C. F., \& Nguyen, Q. (2016). Risk and Time Preferences: Linking Experimental and Household Survey Data from Vietnam. In S. Ikeda, H. K. Kato, F. Ohtake, \& Y. Tsutsui (Eds.), Behavioral Economics of Preferences, Choices, and Happiness (pp. 3-25). Berlin: Springer.

Townsend, P. (1962). The Meaning of Poverty. The British Journal of Sociology, 13, 210-227. http://dx.doi.org/10.2307/587266

Tu, Y. J., \& Guo, Y. Y. (2011). The Influence of Life-Events on Negative Emotions: Social Support as a Moderator and Coping Style as a Mediator. Chinese Journal of Clinical Psychology, 5, 652 655.

Tversky, A., \& Shafir, E. (1992). Choice under conflict: The Dynamics of Deferred Decision. Psychological Science, 3, 358-361.

Vohs, K. D., Baumeister, R. F., Schmeichel, B. J., Twenge, J. M., Nelson, N. M., \& Tice, D. M. (2014). Making Choices Impairs Subsequent Self-Control: A Limited-Resource Account of Decision Making, Self-Regulation, and Active Initiative. Journal of Personality and Social Psychology, 94, 883-898. http://dx.doi.org/10.1037/2333-8113.1.s.19

WHO (2013). World Health Statistics 2013. Geneva.

Wittchen, H. U., Zhao, S., Kessler, R. C., \& Eaton, W. W. (1994). DSM-III-R Generalized Anxiety Disorder in the National Comorbidity Survey. Archives of General Psychiatry, 51, 355-364. http://dx.doi.org/10.1001/archpsyc.1994.03950050015002 
Xue, C. X., Lu, L., \& Liang, Z. Q. (2010). Investigation about the Depression of Poor College Students. China Journal of Health Psychology, 7, 853-854.

Yesuf, M., \& Bluffstone, R. (2008). Wealth and Time Preference in Rural Ethiopia (No. $d p-08-16-e f d)$.

Submit or recommend next manuscript to SCIRP and we will provide best service for you:

Accepting pre-submission inquiries through Email, Facebook, LinkedIn, Twitter, etc. A wide selection of journals (inclusive of 9 subjects, more than 200 journals)

Providing 24-hour high-quality service

User-friendly online submission system

Fair and swift peer-review system

Efficient typesetting and proofreading procedure

Display of the result of downloads and visits, as well as the number of cited articles Maximum dissemination of your research work

Submit your manuscript at: http://papersubmission.scirp.org/ 